\title{
Budgetary Impact of Cabazitaxel Use After Docetaxel Treatment for Metastatic Castration-Resistant Prostate Cancer
}

\author{
Kyle Flannery, PharmD; Ed Drea, PharmD; Louis Hudspeth, PhD; \\ Shelby Corman, PharmD, MS, BCPS; Xin Gao, PhD; Mei Xue, MBA; and Raymond Miao, MS
}

\begin{abstract}
BACKGROUND: With the approval of several new treatments for metastatic castration-resistant prostate cancer (mCRPC), budgetary impact is a concern for health plan decision makers. Budget impact models (BIMs) are becoming a requirement in many countries as part of formulary approval or reimbursement decisions. Cabazitaxel is a second-generation taxane developed to overcome resistance to docetaxel and is approved for the treatment of patients with $\mathrm{MCRPC}$ previously treated with a docetaxelcontaining regimen.
\end{abstract}

OBJECTIVE: To estimate a 1-year projected budget impact of varying utilization rates of cabazitaxel as a second-line treatment for mCRPC following docetaxel, using a hypothetical U.S. private managed care plan with 1 million members.

METHODS: A BIM was developed to evaluate costs for currently available treatment options for patients with mCRPC previously treated with docetaxel. Treatments included in the model were cabazitaxel, abiraterone acetate, enzalutamide, and radium-223, with utilization rates derived from market research data. Medication costs were calculated according to published pricing benchmarks factored by dosing and duration of therapy as stated in the prescribing information for each agent. Published rates and costs of grade 3-4 adverse events were also factored into the model. In addition, the model reports budget impact under 2 scenarios. In the first base-case scenario, patient out-of-pocket costs were subtracted from the total cost of treatment. In the second scenario, all treatment costs were assumed to be paid by the plan.

RESULTS: In a hypothetical 1 million-member health plan population, 100 patients were estimated to receive second-line treatment for mCRPC after treatment with docetaxel. Using current utilization rates for the 4 agents of interest, the base-case scenario estimated the cost of second-line treatment after docetaxel to be $\$ 6,331,704$, or $\$ 0.528$ per member per month (PMPM). In a scenario where cabazitaxel use increases from the base-rate case of $24 \%$ to a hypothetical rate of $33 \%$, the PMPM cost would decrease to $\$ 0.524$, reflecting a cost saving of $\$ 0.004$ PMPM and equating to incremental savings of $\$ 49,546$, or $\$ 497$ per patient per year (PPPY). In the second scenario, when out-of-pocket costs were not considered, the cost of second-line treatment after docetaxel was estimated as $\$ 6,733,594$, or $\$ 0.561$ PMPM. With a hypothetical increase in cabazitaxel use (24\%-33\%), the PMPM cost would decrease to $\$ 0.554$, reflecting savings of $\$ 0.007$ PMPM and equating to incremental savings of $\$ 86,136$, or $\$ 864$ PPPY. The primary driver of cost savings with increased cabazitaxel use was lower acquisition cost. One-way sensitivity analyses revealed that the model results were robust over a wide range of input values (utilization, prevalence, and population parameters).

CONCLUSIONS: In the presented BIM, an increase in cabazitaxel use is expected to result in modest cost savings to the health plan. Patient coinsurance savings may also be realized based on applicable Medicare Part $B$ and Part D calculations. This BIM presents an objective, comprehensive, robust, and user-adaptable tool that health plans and medical decision makers may use to evaluate potential economic impact of formulary and reimbursement decisions.

J Manag Care Spec Pharm. 2017;23(4):416-26

Copyright $\odot 2017$, Academy of Managed Care Pharmacy. All rights reserved.

\section{What is already known about this subject}

Only a small proportion of patients with prostate cancer will progress to metastatic castration-resistant disease (mCRPC) and go on to receive second-line therapy after previous docetaxel regimens, yet significant increases in the use of medical resources and costs have been observed following first-line docetaxel treatment. Several new treatments for mCRPC have been approved in recent years; however, there are no head-to-head trials comparing these agents, and health plan decision makers are concerned with the budgetary impact of these new treatment regimens.

Budget impact models are useful tools and are increasingly becoming a requirement in many countries before formulary approval or reimbursement.

\section{What this study adds}

This study is the first to incorporate patient out-of-pocket costs, as well as health plan costs, in a primary analysis assessing the budgetary impact of the use of second-line treatments for mCRPC following docetaxel therapy.

This budget impact model indicates that a hypothetical increase in the cabazitaxel utilization rate from base case (24\%) to estimated (33\%) is expected to result in modest cost savings for the health plan and the patient.

Sensitivity analyses revealed that the model results are robust over a wide range of input values.

Ј n 2013, there were an estimated 2,850,139 men living with prostate cancer in the United States. ${ }^{1,2}$ It is predicted that 180,890 new cases of prostate cancer will have been diagnosed in 2016, representing approximately 11\% of newly diagnosed cancers in men. ${ }^{3}$ In men with prostate cancer, metastatic disease occurs at an estimated frequency of $4 \%$ with a relatively low 5-year overall survival rate of $29 \% .^{2}$ Of patients diagnosed with prostate cancer, $10 \%-20 \%$ of patients will develop 
castration-resistant disease within 5 years. Furthermore, at least $84 \%$ of patients were shown to have metastases at diagnosis of castration-resistant prostate cancer (CRPC). ${ }^{4}$

There are currently no curative options for patients with metastatic castration-resistant prostate cancer (mCRPC), also known as metastatic hormone-refractory prostate cancer. Current guidelines recommend administration of docetaxel in combination with prednisone, enzalutamide, or abiraterone acetate plus prednisone as first-line treatment options. Other options include sipuleucel-T in asymptomatic or minimally symptomatic patients with good performance status and radium-223 in patients with bone metastases and no visceral metastases. ${ }^{5}$ Before 2010, there were no treatment options approved by the U.S. Food and Drug Administration (FDA) for patients with mCRPC progressing after first-line docetaxel. However, current FDA-approved and National Comprehensive Cancer Network (NCCN)-recommended second-line treatments for mCRPC following docetaxel therapy now include abiraterone acetate plus prednisone, enzalutamide, cabazitaxel plus prednisone, radium-223, and sipuleucel-T. ${ }^{5,6}$

Cabazitaxel is a second-generation taxane developed to overcome resistance to docetaxel and is approved for the treatment of patients with mCRPC previously treated with a docetaxel-containing regimen. ${ }^{6,7}$ In preclinical models, cabazitaxel exhibited similar activity to docetaxel in docetaxel-sensitive tumors but had increased activity in tumors resistant to docetaxel. ${ }^{8}$ In the pivotal phase III TROPIC trial that studied patients with mCRPC who had previously received docetaxel, survival was longer with cabazitaxel plus prednisone compared with mitoxantrone plus prednisone (median overall survival=15.1 vs. 12.7 months, respectively; $P<0.0001$ ) and risk of death was reduced by $30 \%$. ${ }^{9}$

The clinical efficacy of cabazitaxel, abiraterone, enzalutamide, and radium-223 in patients with $\mathrm{mCRPC}$ is well documented, with all 4 agents providing a survival benefit in the second-line setting. ${ }^{9-12}$ However, there are no head-to-head trials comparing these agents, and current observational evidence provides no clear consensus on the preferred sequence of therapies following docetaxel. ${ }^{13-16}$ If efficacy is assumed to be equivalent after use of docetaxel, health plan decision makers will analyze the budgetary impact of these new treatment regimens to minimize costs without the expense of health benefits lost. In a 2011 publication, an analysis using data from the Surveillance, Epidemiology, and End Results databases (1991-2002) for patients aged $\geq 65$ years estimated that in the United States the lifetime total costs (in 2004 U.S. dollars) for a single patient diagnosed with prostate cancer was $\$ 110,520$, and prostate cancer-related costs accounted for approximately $31 \%$ of the total cost $(\$ 34,432) .{ }^{17}$ In patients with mCRPC, significant increases in the use of medical resources (hospitalizations and emergency room, physician, and ambulatory visits) and costs have been observed following first-line docetaxel treatment. ${ }^{19}$ Regarding individual patients, monthly copay/coinsurance costs associated with chemotherapy agents are often extremely high, and for some patients, these costs are likely to negatively affect adherence. ${ }^{20}$ To assess the economic consequences of adopting new drug therapies, budget impact models (BIMs) are important tools that are increasingly being used to support coverage and reimbursement decisions.

The objective of this study was to develop a BIM to assess the economic impact of a hypothetical increase, for illustration purposes only, in the use of cabazitaxel as a treatment for mCRPC after docetaxel treatment for a hypothetical private U.S. managed care plan with 1 million members.

\section{Methods}

\section{Model Overview}

This budget impact analysis was developed to evaluate the costs of currently available treatment options for patients with mCRPC previously treated with docetaxel, from the perspective of a U.S. managed care plan. The default, or base case, used is a hypothetical membership of 1 million, but this can be modified and scaled to reflect actual plan membership numbers.

This 1-year projected budget impact analysis primarily focused on the costs of chemotherapy, radium therapy, or androgen receptor-targeted therapy and associated grade 3 and 4 adverse events (AEs). Epidemiology inputs for the patient population, dosing information, and rates of grade 3 and 4 AEs and their associated costs, as well as therapy utilization rates, were included in the model. Clinical efficacy was not included as an outcome.

The median number of treatment cycles over 12 months was used to calculate treatment cost. Consistent with recommended budget impact analysis guidelines, discounting of costs was not incorporated into the current model because of the endpoints assessed and the short length of the model time horizon (12 months). ${ }^{21}$ The model was constructed using Microsoft Excel 2007 supplemented with Visual Basic programming to ensure its transparency and user friendliness (Microsoft, Redmond, WA).

Through understanding of the base-case analysis, health system decision makers have the ability to analyze plan-specific data in order to determine the 12-month budgetary impact of varying cabazitaxel utilization rates among mCRPC patients previously treated with docetaxel.

\section{Patient Population Estimates}

U.S. census data were combined with population-based mCRPC prevalence data to estimate the prevalence of prostate cancer in a hypothetical 1 million-member health plan population. The population was assumed to be $49.2 \%$ male, ${ }^{22}$ with a prostate cancer prevalence of $1.6885 \% .{ }^{23}$ Based on a previously published dynamic progression model that incorporated incidence, progression, and mortality, the proportion of patients with mCRPC progressing after treatment with docetaxel was estimated to be $1.20 \% .^{24}$ 


\begin{tabular}{l|c|c|c}
\hline \multicolumn{1}{c|}{ TABLE 1 } & \multicolumn{2}{c}{$\begin{array}{c}\text { Pivotal Phase III Studies of Agents Used } \\
\text { in Second-Line Treatment of mCRPC: } \\
\text { Median Duration of Treatment }\end{array}$} \\
\hline $\begin{array}{l}\text { Treatment } \\
\begin{array}{l}\text { Abiraterone } \\
\text { acetate plus } \\
\text { prednisone }\end{array}\end{array}$ & $\begin{array}{c}\text { Clinical } \\
\text { Trial }\end{array}$ & $\begin{array}{c}\text { Median Duration } \\
\text { of Therapy }\end{array}$ & $\begin{array}{c}\text { Data } \\
\text { Source6,25-27 }\end{array}$ \\
\hline $\begin{array}{l}\text { Cabazitaxel plus } \\
\text { prednisone }\end{array}$ & TROPIC & 8.0 months & $\begin{array}{c}\text { ZYTIGA (abiraterone } \\
\text { acetate) PI, revised } \\
\text { May 2016 }\end{array}$ \\
\hline Enzalutamide & AFFIRM & 8.3 months & $\begin{array}{c}\text { JEVTANA } \\
\text { (cabazitaxel) PI, } \\
\text { revised October 2016 }\end{array}$ \\
\hline Radium-223 & ALSYMPCA & 6 injections & $\begin{array}{c}\text { XTANDI } \\
\text { (enzalutamide) PI, } \\
\text { revised October 2016 } \\
\text { dichloride) PI, revised } \\
\text { May 2013 }\end{array}$ \\
\hline
\end{tabular}

$\overline{m C R P C}=$ metastatic castration-resistant prostate cancer; $P I=$ prescribing information.

\section{Treatment Options and Duration}

To estimate the budget impact of varying cabazitaxel use after docetaxel treatment on patients with mCRPC and within a health plan formulary, comparative second-line agents were included in the model based on the following criteria: The agents must be indicated for MCRPC after docetaxel treatment, and the agents must be recommended by NCCN (category 1) for patients progressing after docetaxel. ${ }^{5}$ Based on this rationale, 4 treatment options for use after docetaxel were included in the analysis: cabazitaxel, abiraterone acetate, enzalutamide, and radium-223.

The median duration of therapy for each second-line treatment was sourced from the respective prescribing information documentation, as based on the pivotal phase III clinical trials in mCRPC for each of the agents (Table 1). It was assumed that treatment remained stable throughout the 12-month period, and no switching and/or dose modification occurred. It was also assumed that median treatment duration reflected the patient population time horizon, and all treatments occurred within the identified 12-month period.

\section{Medication Costs}

Doses were calculated based on recommended dosing taken from the respective prescribing information. ${ }^{6,25-27}$ Mean weight and body surface area (BSA) were assumed to be $75 \mathrm{~kg}$ and $2.01 \mathrm{~m}^{2} .^{28}$ Drug costs were determined using methods reported in the Academy of Managed Care Pharmacy Guide to Pharmaceutical Payment Methods Version 3.0. ${ }^{29}$ Similar costing methods were used in a previously published budget impact analysis that approximated health plan costs for prostate cancer. ${ }^{30}$ Costs for oral medications were calculated as average wholesale price (AWP) minus $16 \%,{ }^{31}$ and costs for infused drugs were calculated as average sales price (ASP) plus $6 \%{ }^{32}$ Radium-223 does not have a documented ASP in the
Centers for Medicare \& Medicaid Services (CMS) July 2015 ASP Pricing File. Because it is a radiopharmaceutical, radium-223 is assigned a wholesale acquisition cost (WAC) price per microcurie by CMS, and its cost was calculated in this analysis by multiplying the WAC price by the calculated dose. The cost of oral prednisone tablets for abiraterone or cabazitaxel treatment was not considered in this model because it would add less than $0.02 \%$ to the total cost of either therapy. Medication costs are summarized in Table 2A.

\section{Out-of-Pocket Costs}

Additionally, this budget impact analysis took into account coinsurance and incorporated patient out-of-pocket (OOP) costs into the base-case calculation. In the base-case scenario, costs are calculated using the 2015 Medicare Part B (for cabazitaxel and radium-223) and Part D (for abiraterone acetate and enzalutamide) Standard Drug Benefit structures. ${ }^{33}$ Patients with Medicare Part B pay a 20\% coinsurance for Medicare-approved services after meeting their deductible; the proportion of these patients with supplementary insurance or Medigap policies are assumed to pay no coinsurance, since their $20 \%$ cost share for approved services will be fully remunerated by their supplementary policy. ${ }^{34}$ The proportion of Medicare patients with supplementary insurance was estimated at $90 \%$ in $2010 .^{35}$ Patient OOP costs for injected treatments (Medicare Part B) are summarized in Table 2B. ${ }^{33}$ For oral medications, it was assumed that all patients with mCRPC exceeded the Medicare Part D catastrophic coverage limit in total annual drug costs. Thus, OOP costs were calculated as the sum of the deductible (\$320), costs incurred during the initial coverage period (\$660) and during the coverage gap ( $\$ 1674$, assuming use of branded medications), and $5 \%$ coinsurance for all treatment costs over the catastrophic coverage threshold of $\$ 6,680 .{ }^{36,37}$

\section{Adverse Events}

Grade 3-4 AE incidence rates for each agent were taken from the respective product labeling. ${ }^{6,25-27}$ AEs for which there is no treatment, AEs considered to be disease related rather than treatment related (e.g., spinal cord compression), and AEs for which the incidence weighted average cost-per-patient equaled less than $\$ 25$ were excluded. For AEs that were not mutually exclusive (e.g., neutropenia and leukopenia), only the most frequent $\mathrm{AE}$ was included.

Based on these criteria, anemia, neutropenia, febrile neutropenia, hypokalemia, and thrombocytopenia were included in the model. AE cost values were taken from a previous BIM in mCRPC and adjusted from December 2013 U.S. dollars to April 2015 U.S. dollars using the medical care component of the Consumer Price Index (Table 2C). ${ }^{30,38}$

\section{Treatment Utilization}

Use of the 4 treatments after docetaxel under the current scenario (actual utilization rates as of January 2015; unpublished 
TABLE 2 Costs Used in Budget Impact Model: Medication Costs, Patient Out-of-Pocket Costs for Injected Treatments (Medicare Part B), and Incidence Rate of Adverse Events and Associated Costs

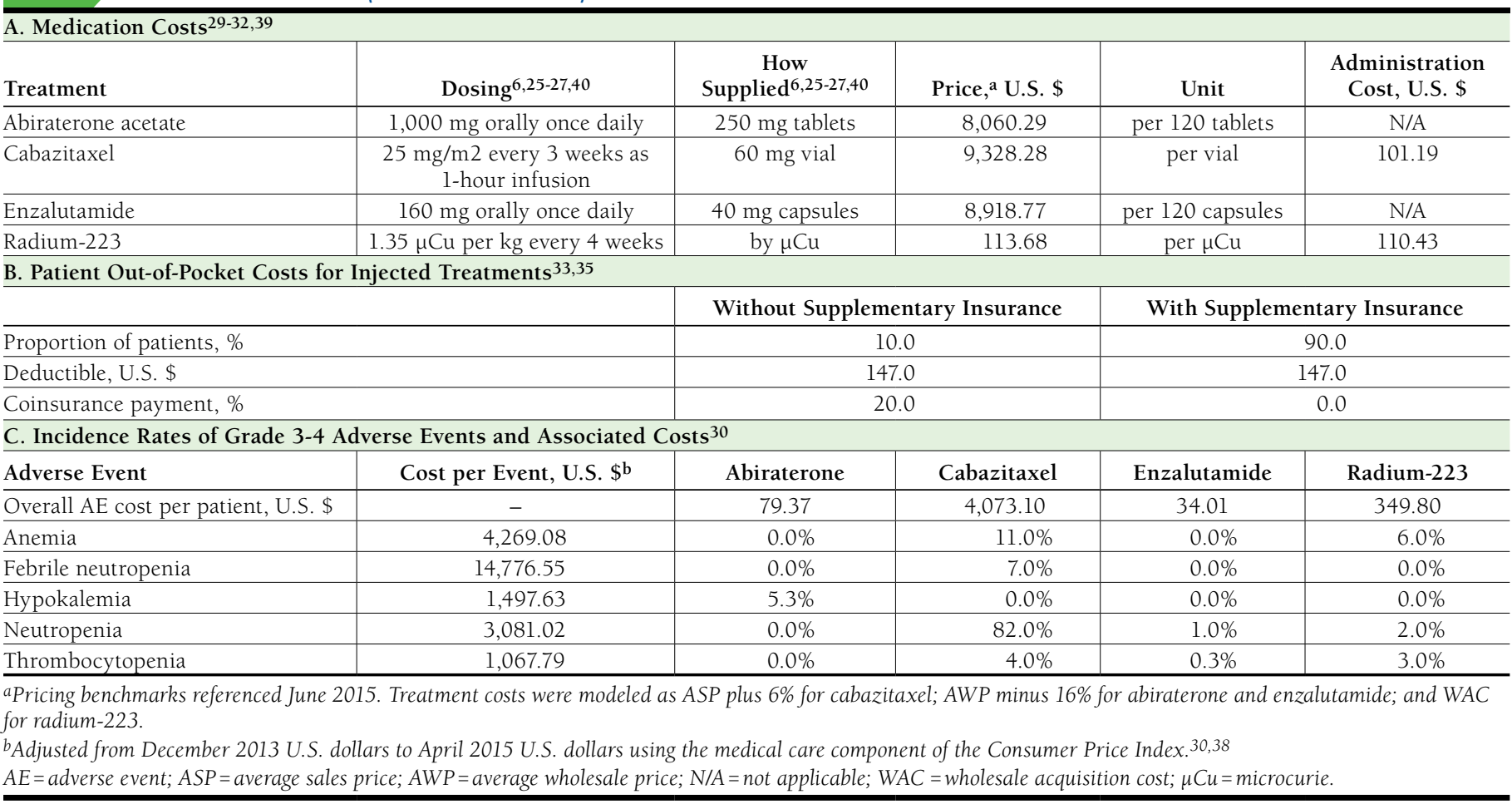

data, IMS Health, 2015) and in a theoretical future scenario, for illustration purposes only, is shown in Table 3A.

\section{Model Assumptions}

Key model assumptions used in the base-case analysis are summarized in Appendix A (available in online article).

\section{Analytical Methodology}

The total cost of treatment for each therapy was calculated as the sum of medication (treatment cost plus administration cost) and management of AE costs. Under the base-case scenario, medication costs were separated into plan costs and patient OOP costs. The total cost of mCRPC treatments after treatment with docetaxel was then calculated by incorporating population size and utilization rate for each therapy under the current and future scenarios, with the difference representing the overall change in total plan costs per year.

Total cost per member per month (PMPM) and per member per year (PMPY) was calculated by dividing the total plan cost per month or year (less any patient OOP costs), respectively, by the number of members in the plan. Per-patient-per-year (PPPY) costs were calculated by dividing the total plan cost per year by the total number of patients receiving second-line therapy for mCRPC.
All cost outputs were expressed in 2015 U.S. dollars. The initial base-case analysis was populated with literature-based inputs, and one-way sensitivity analyses were conducted to examine the robustness of the model over a range of potential input values.

\section{Results}

In a hypothetical private U.S. health plan population of 1 million members, the estimated number of men with MCRPC who will receive treatment after disease progression following docetaxel therapy was calculated to be 100 patients. ${ }^{24}$

The estimated 1-year cost of treating a single patient with mCRPC with second-line cabazitaxel was $\$ 60,650$, which included the cost of chemotherapy $(\$ 56,577)$ and management of grade 3 and 4 AEs $(\$ 4,073$; Table 3B).

\section{Base-Case Analysis: Patient 00P Costs Considered}

In the base-case scenario, patient OOP costs were calculated and excluded from the total cost of cabazitaxel. Under the current Medicare Part B fee structure, $\$ 55,301$ of the total cost of cabazitaxel would be paid by the health plan, and $\$ 1,276$ would be paid by the patient (Table 3B).

Based on a hypothetical health care plan with 1 million members, the cost of second-line treatment of mCRPC using current utilization rates of the 4 agents of interest was 


\begin{tabular}{|c|c|c|c|c|c|c|}
\hline TAB & \multicolumn{6}{|c|}{$\begin{array}{l}\text { For Patients with mCRPC Previously } \\
\text { Treated with Docetaxel Included in } \\
\text { Budget Impact Model: Utilization } \\
\text { Rates of Second-Line Treatments and } \\
\text { Treatment Costs PPPY }\end{array}$} \\
\hline \multicolumn{7}{|c|}{ A. Utilization Rates of Treatments } \\
\hline \multicolumn{2}{|c|}{ Therapeutic Option } & \multicolumn{2}{|c|}{$\begin{array}{c}\text { Current } \\
\text { Scenario, \% }\end{array}$} & \multicolumn{2}{|c|}{$\begin{array}{c}\text { Future } \\
\text { Scenario, \% }\end{array}$} & Change, \% \\
\hline \multicolumn{2}{|l|}{ Abiraterone } & \multicolumn{2}{|c|}{34.0} & & 30.0 & -4.0 \\
\hline \multicolumn{2}{|l|}{ Cabazitaxel } & \multicolumn{2}{|c|}{24.0} & & 33.0 & 9.0 \\
\hline \multicolumn{2}{|l|}{ Enzalutamide } & \multicolumn{2}{|c|}{26.0} & & 22.0 & -4.0 \\
\hline \multicolumn{2}{|l|}{ Radium-223 } & \multicolumn{2}{|c|}{16.0} & & 15.0 & -1.0 \\
\hline \multicolumn{2}{|l|}{ Total } & \multicolumn{2}{|c|}{100.0} & & 100.0 & 0.0 \\
\hline \multicolumn{7}{|c|}{ B. Treatment Costs PPPYa } \\
\hline $\begin{array}{l}\text { Model } \\
\text { Treatment }\end{array}$ & \multicolumn{2}{|c|}{$\begin{array}{c}\text { Medication } \\
\text { Cost to Health } \\
\text { Plan, U.S. \$ }\end{array}$} & \multicolumn{2}{|c|}{$\begin{array}{l}\text { Medication } \\
\text { Cost to } \\
\text { Patient, } \\
\text { U.S. } \$\end{array}$} & $\begin{array}{c}\text { Adverse Event } \\
\text { Cost, U.S. \$ }\end{array}$ & $\begin{array}{l}\text { Total Cost, } \\
\text { U.S. \$ }\end{array}$ \\
\hline Abiraterone & \multicolumn{2}{|c|}{59,789} & \multicolumn{2}{|c|}{5,589} & 79 & 65,457 \\
\hline Cabazitaxel & \multicolumn{2}{|c|}{55,301} & \multicolumn{2}{|c|}{1,276} & 4,073 & 60,650 \\
\hline Enzalutamide & \multicolumn{2}{|c|}{68,981} & \multicolumn{2}{|c|}{6,073} & 34 & 75,088 \\
\hline Radium-223 & 68, & & 1,539 & & 350 & 70,073 \\
\hline \multicolumn{7}{|c|}{$\begin{array}{l}{ }^{a} \text { Cost calculations assume the median duration of therapy as indicated in prescrib- } \\
\text { ing information for each agent. } \\
\text { bAssumes Medicare Part B and Part D fee structures. }{ }^{33}\end{array}$} \\
\hline
\end{tabular}

estimated to be $\$ 6,331,704$ or $\$ 0.528$ PMPM. Assuming that the utilization rate of cabazitaxel increased from $24 \%$ in the current base-case scenario to a hypothetical $33 \%$ in the future scenario, the PMPM cost would decrease to $\$ 0.524$, reflecting cost savings of $\$ 0.004 \mathrm{PMPM}$. These calculations equate to incremental cost savings of $\$ 49,546$, or $\$ 497$ PPPY compared with the current scenario (Figure 1A).

\section{Alternative Scenario: Patient 00P Costs Not Considered}

In an alternative scenario, patient OOP costs were not calculated, so all costs were assumed to be paid by the plan. In this scenario, the cost for treatment of MCRPC after docetaxel treatment using current utilization rates was estimated to be $\$ 6,733,594$, or $\$ 0.561$ PMPM. Assuming, as stated in the previous scenario, that the utilization rate of cabazitaxel increased from $24 \%$ to $33 \%$, PMPM cost would decrease to $\$ 0.554$, reflecting cost savings of $\$ 0.007$ PMPM. These calculations equate to incremental cost savings of $\$ 86,136$, or $\$ 864$ PPPY (Figure 1B).

\section{Sensitivity Analyses}

One-way sensitivity analyses revealed that the model results were robust over a wide range of input values. Most scenarios indicated cost savings with future increases in cabazitaxel use in $\mathrm{mCRPC}$ patients after treatment with docetaxel. Utilization, prevalence, and population parameter inputs were modified to assess changes in total annual plan costs. The only scenario that resulted in increased plan costs with expanded future cabazitaxel utilization was significant increases to the average population BSA (Figure 2).

Population average body weight, BSA, and supplementary coverage rates were modified to assess changes in annual patient OOP costs. When the average patient BSA in the population was $3.0 \mathrm{~m}^{2}$, annual patient OOP costs were $\$ 856$ higher with cabazitaxel versus radium-223. When the average patient body weight in the population was $50 \mathrm{~kg}$, annual patient OOP costs were $\$ 197$ higher with cabazitaxel versus radium-223. All other scenarios resulted in patient cost savings with cabazitaxel versus comparators (cost savings ranged from \$131 to $\$ 5,361$ annually, see Appendix B, available in online article).

\section{Discussion}

In patients with mCRPC previously treated with docetaxel, cabazitaxel plus prednisone has been shown to improve overall survival and was subsequently approved for the second-line treatment of patients with mCRPC. ${ }^{6,79}$ In light of new therapies, and to assist health care decision makers, the present model was developed to estimate the budget impact of increased use of cabazitaxel as a second-line treatment for advanced mCRPC following docetaxel, within a health plan formulary of a private managed care plan in the United States. An asset of this BIM was the consideration of patient OOP costs-analysis of patient OOP costs is a unique feature of this model.

Based on the results of adding cabazitaxel to a hypothetical health plan of 1 million members, assuming an increase in use from a base case of $24 \%$ to a hypothetical $33 \%$ for cabazitaxel, the total budget impact was $-\$ 0.004$ PMPM when OOP costs were taken into consideration and -\$0.007 PMPM when OOP costs were not considered, so both scenarios corresponded to modest cost savings. Overall, AE costs associated with cabazitaxel were higher than other second-line treatments, but these costs were offset by lower treatment acquisition costs, resulting in a net saving with cabazitaxel. The overall budget impact of future increases in cabazitaxel use was thus expected to be minimal, with modest cost savings anticipated.

The results of this analysis can be compared with a previous publication of budget impact results for $\mathrm{mCRPC}$ in which an average incremental cost increase of $\$ 0.0112$ PMPM was reported in association with adoption of abiraterone. ${ }^{30}$ The abiraterone BIM is similar to this cabazitaxel BIM in that both reported only a small overall budget impact from shifting utilization rates of second-line mCRPC treatments. This modest budget impact was likely driven by the small percentage of patients (ranging from 57 to 100 patients from a plan population of 1 million) eligible for second-line therapy in this setting. It is important to note the differences in the therapeutic landscape used in each BIM. This cabazitaxel BIM included enzalutamide and radium-223, whereas at the time of publication, the abiraterone BIM did not. Changes in medication prices over 


\section{FIGURE 1 Total Plan Cost of mCRPC Treatments After Docetaxel: Excluding Out-of-Pocket Costs} and Including All Costs Paid by Plan

A. Excluding Out-of-Pocket Costs

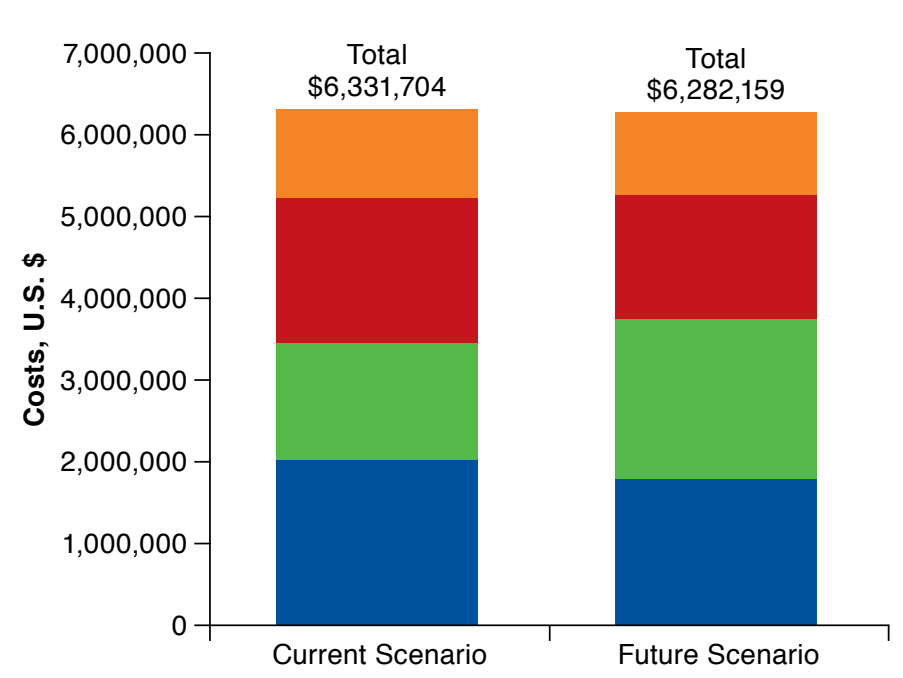

B. Including All Costs Paid by Plan

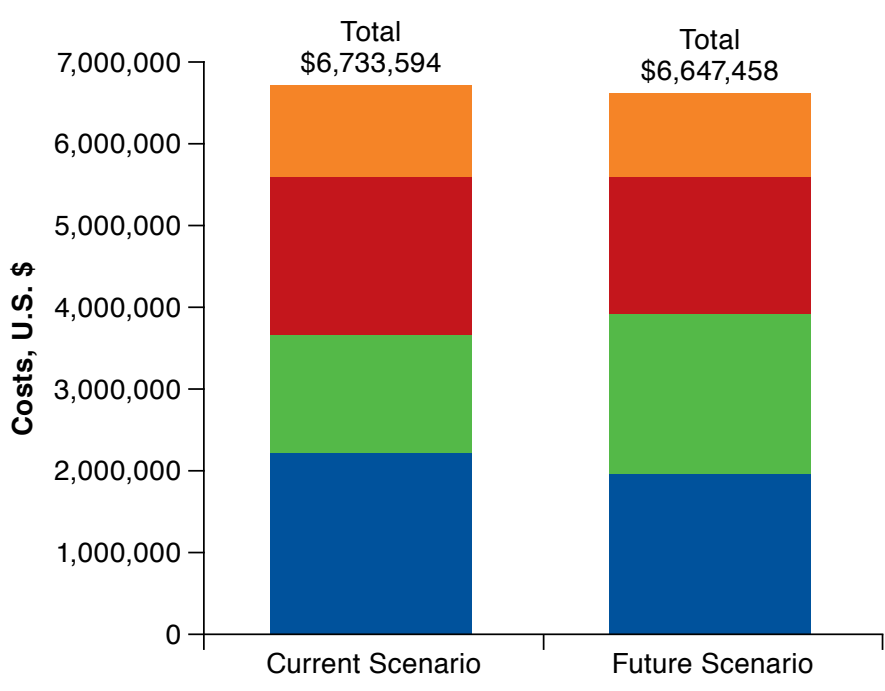

Radium-223 Enzalutamide

Cabazitaxel Abiraterone

time could also significantly affect budgetary impact. Results from each BIM may not be entirely comparable, which highlights the importance of updating pharmacoeconomic analyses longitudinally if important cost drivers change.

It is important to acknowledge that BIMs can only approximate reality, so results in the real world may differ. A situation that has been historically difficult to model is the comprehensive incorporation of AE costs. The inclusion/exclusion criteria for AE cost representation in this model were developed a priori and were intended to represent an objective approximation of the most important costs to a health plan's annual budget. Several potential AEs were excluded from costing based on low incidence or minimal population-weighted average cost per patient. This exclusion is necessary to minimize the complexity of the model and to keep the model simple, transparent, and focused on the most significant cost drivers. It should be noted that the final AE costing scheme may be biased against cabazitaxel, since 4 of the 5 AEs included in the BIM were primarily related to cabazitaxel therapy. Nonetheless, it is important to adhere to the objectively defined a priori research methods and recognize the limitations inherent in the costing of AEs.

Wastage of medication is a consideration when drawing conclusions from the budget impact analysis. Cabazitaxel is available as a $60 \mathrm{mg}$ single-use vial to support $25 \mathrm{mg} / \mathrm{m}^{2}$ dosing, but because of a range of patient BSAs, allocation of certain doses could result in wastage. Wastage with cabazitaxel was accounted for within this BIM by rounding up all calculated doses to the next whole vial integer. This approach conservatively estimates the cost benefit of cabazitaxel, since approaches may exist in clinical practice to reduce wastage where it might otherwise occur. Any such approaches would reduce total treatment costs of cabazitaxel and thus increase cost savings beyond the conservative estimates from this BIM.

Uncertainty in model results is often mitigated by a sensitivity analysis. In this study, the one-way analyses revealed sensitivity to population average BSA, with an additional total annual plan cost of $\$ 442,572$ realized when this parameter was extended to $3.0 \mathrm{~m}^{2}$. This result is not particularly concerning to the health plan budgeter, since it is very unlikely that in the real world an entire patient population would have an average parameter this extreme-a population of 5'10" men would need to average a body weight of approximately 400 lbs to reach a BSA of $3.0 \mathrm{~m}^{2}$. Considering the analysis of average patient OOP costs, at the bounds of the sensitivity ranges, the results indicated strong durability for patient cost savings with cabazitaxel. Sixteen of eighteen potential comparisons revealed cost savings with cabazitaxel versus comparators.

\section{Limitations}

There are some limitations to consider when interpreting the results of this model. There is a paucity of information regarding the actual prevalence of patients with mCRPC in different regions, so results may not reflect the real-world market for every patient population. In addition, the model does not 


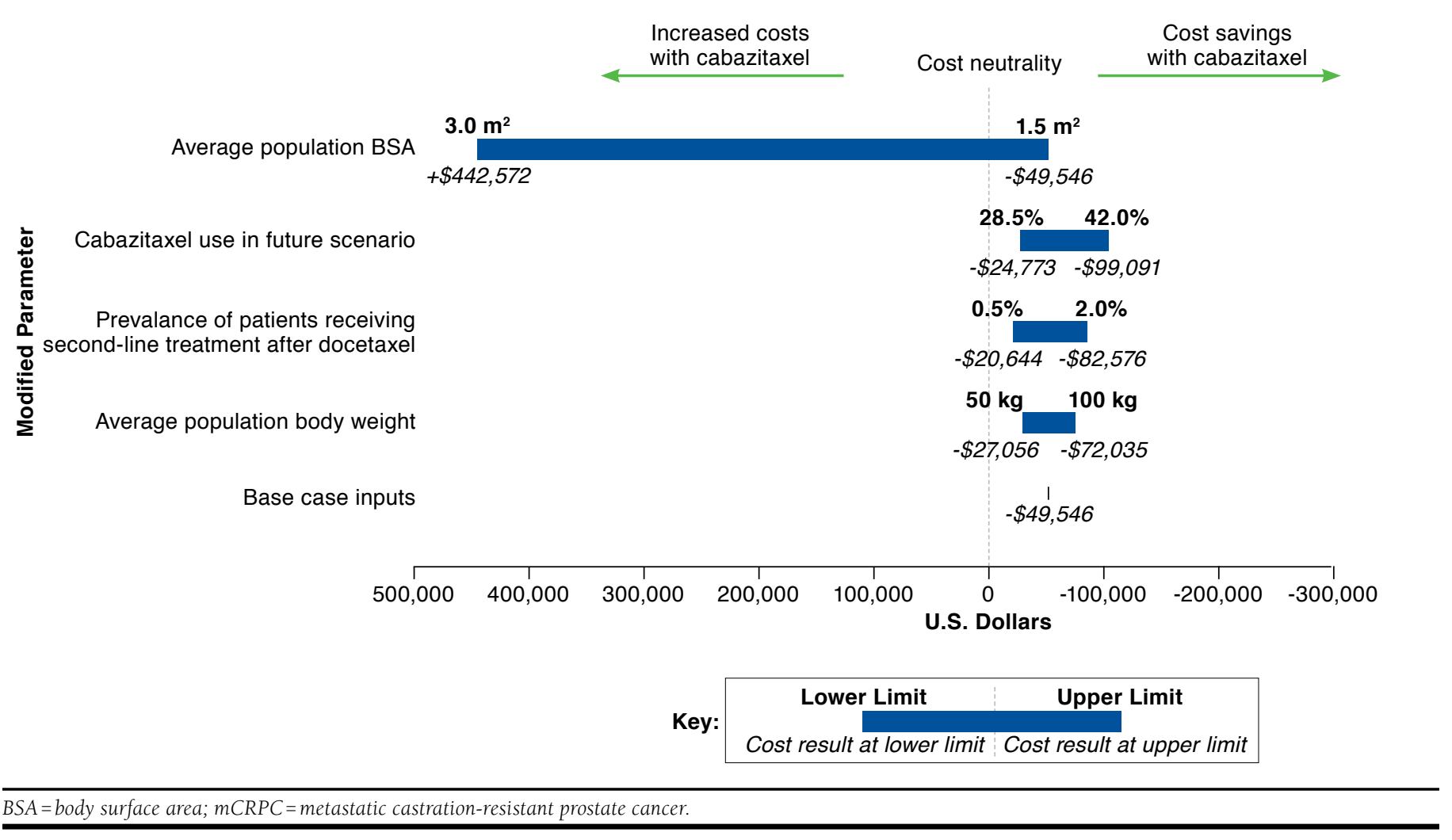

consider off-label medication use or those medications that did not receive a category 1 recommendation in the most recent NCCN guidelines. ${ }^{5}$

For this budget analysis, several assumptions were made regarding treatment duration. It was assumed that treatment was stable throughout the time horizon, with no switching, discontinuations, and/or dose alterations. Also, in reality, clinical endpoints such as efficacy and survival would affect any assumptions related to treatment duration. For example, patients who demonstrate a positive response to therapy are likely to have increased survival, would be treated for a longer duration, and would, consequently, incur greater treatment costs. In contrast, a patient who does not respond, becomes intolerant, or dies will be treated for a shorter period of time (and thus incurs lower treatment costs). The model also assumes that patients were fully compliant with treatment regimens and dosing recommendations, which may not be the case in real-world practice. Notably, the current model uses median treatment cycles based on current prescribing information. However, the real-world median treatment cycles of cabazitaxel, abiraterone acetate, enzalutamide, and radium-223 over the 12-month time horizon could be different versus the base-case inputs used.
Another possible limitation of the model is that AE rates were obtained from different clinical trials. Future studies should be conducted to ascertain direct head-to-head comparisons of real-world effectiveness, AE rates, and economic outcomes. For the OOP coinsurance rates, the model assumed a Medicare plan design because the median age of patients with mCRPC is greater than 65 years according to clinical studies and current literature. However, in reality patients could have a variety of different coinsurance rates, but this would only affect the Medicare insurance rate; budget impacts and treatment costs would remain unchanged. Also, with regards to the Medicare plan, it is assumed that all patients were Medicare eligible.

Finally, the applicability of the model may change over time because of changes in costs, prevalence rates, clinical characteristics of the patient populations, treatment options, and health care formulary or coverage decisions. Given these limitations, it is recommended that stakeholders consider individualized budget calculations using assumptions derived from population-specific medical and pharmacy claims data.

\section{Conclusions}

BIMs are valuable tools for health plans and medical decision makers to make more comprehensively informed 
pharmacoeconomic assessments on formulary inclusion and coverage decisions. The present model was developed to estimate the budgetary impact of an increased use of cabazitaxel within a U.S. health plan as second-line treatment for mCRPC patients following docetaxel therapy. An increase in the cabazitaxel utilization rate from a base case $24 \%$ to a hypothetical $33 \%$ would be expected to have a minimal budgetary impact, with modest cost savings anticipated for the patient and the health plan.

\section{Authors}

KYLE FLANNERY, PharmD; ED DREA, PharmD; LOUIS HUDSPETH, PhD; and RAYMOND MIAO, MS, North America Medical Affairs, Evidence Based Medicine Division, Sanofi US, Bridgewater, New Jersey. SHELBY CORMAN, PharmD, MS, BCPS; XIN GAO, PhD; and MEI XUE, MBA, Pharmerit International, Bethesda, Maryland.

AUTHOR CORRESPONDENCE: Ed Drea, PharmD, Sanofi US, 55 Corporate Dr., Bridgewater, NJ 08807. Tel.: 800.981.2491 (Sanofi Medical Information Services); E-mail: edward.drea@sanofi.com.
6. JEVTANA (cabazitaxel) injection, for intravenous use. Prescribing information. Sanofi. October 2016. Available at: http://products.sanofi.us/jevtana/ jevtana.html. Accessed February 18, 2017.

7. JEVTANA (cabazitaxel) $0 \mathrm{mg}$ concentrate and solvent for solution for infusion. Summary of product characteristics. European Medicines Agency. 2011. Available at: http://www.ema.europa.eu/docs/en_GB/document_ library/EPAR___Product_Information/human/002018/WC500104764.pdf. Accessed February 18, 2017

8. Vrignaud P, Sémiond D, Lejeune P, et al. Preclinical antitumor activity of cabazitaxel, a semi-synthetic taxane active in taxane-resistant tumors. Clin Cancer Res. 2013;19(11):2973-83.

9. de Bono JS, Oudard S, Ozguroglu M, et al. Prednisone plus cabazitaxel or mitoxantrone for metastatic castration-resistant prostate cancer progressing after docetaxel treatment: a randomised open-label trial. Lancet. 2010;376(9747):1147-54.

10. Fizazi K, Scher HI, Molina A, et al. Abiraterone acetate for treatment of metastatic castration-resistant prostate cancer: final overall survival analysis of the COU-AA-301 randomised, double-blind, placebo-controlled phase 3 study. Lancet Oncol. 2012;13(10):983-92.

11. Parker C, Nilsson S, Heinrich D, et al. Alpha emitter radium-223 and survival in metastatic prostate cancer. N Engl J Med. 2013;369(3):213-23.

12. Scher HI, Fizazi K, Saad F, et al. Increased survival with enzalutamide in prostate cancer after chemotherapy. N Engl J Med. 2012;367(13):1187-97.

13. Maines F, Caffo O, Veccia A, Bria E. Sequential use of new agents (NAs) after docetaxel (DOC) first line in metastatic castration-resistant prostate cancer (mCRPC) patients (pts): a pooled-analysis of the published studies. J Clin Oncol. 2015;33(Suppl 7):Abstract 258. Available at: http://meetinglibrary.asco.org/content/141509-159. Accessed February 18, 2017.

14. Oh WK, Miao R, Duh MS, et al. Clinical features and overall survival (OS) in patients (pts) with post-docetaxel (DTX) metastatic castrationresistant prostate cancer (mCRPC) receiving second-line (2L) therapy in the community setting. J Clin Oncol. 2015;33(Suppl 15):Abstract el6029. Available at: http://meetinglibrary.asco.org/content/146444-156. Accessed February 18, 2017.

15. Sonpavde G, Bhor M, Hennessy D, et al. Sequencing of cabazitaxel and abiraterone acetate after docetaxel in metastatic castration-resistant prostate cancer: treatment patterns and clinical outcomes in multicenter communitybased US oncology practices. Clin Genitourin Cancer. 2015;13(4):309-18.

16. Wissing MD, Coenen JL, van den BP, et al. CAST: a retrospective analysis of cabazitaxel and abiraterone acetate sequential treatment in patients with metastatic castrate-resistant prostate cancer previously treated with docetaxel. Int J Cancer. 2015;136(6):E760-E772.

17. Stokes ME, Ishak J, Proskorovsky I, Black LK, Huang Y. Lifetime economic burden of prostate cancer. BMC Health Serv Res. 2011;11:349.

18. Chastek B, Harley C, Kallich J, Newcomer L, Paoli CJ, Teitelbaum AH. Health care costs for patients with cancer at the end of life. J Oncol Pract. 2012;8(6):75s-80s.

19. Mehra M, Wu Y, Dhawan R. Healthcare resource use in advanced prostate cancer patients treated with docetaxel. J Med Econ. 2012;15(5):836-43.

20. D'Amato S. Improving patient adherence with oral chemotherapy. Oncol Issues. 2008;23(4) 42-45.

21. Sullivan SD, Mauskopf JA, Augustovski F, et al. Budget impact analysisprinciples of good practice: report of the ISPOR 2012 Budget Impact Analysis Good Practice II Task Force. Value Health. 2014;17(1):5-14.

22. Howden LM, Meyer JA. Age and sex composition: 2010. 2010 Census Briefs. May 2011. Available at: http://www.census.gov/prod/cen2010/briefs/ c2010br-03.pdf. Accessed February 18, 2017.

23. Howlader N, Noone AM, Krapcho M, et al. SEER cancer statistics review, 1975-2011. Prostate Table 23.15. National Cancer Institute. January 1, 2011. Available at: http://seer.cancer.gov/archive/csr/1975_2011/browse_csr.php?se ctionSEL=23\&pageSEL=sect_23_table.15.html. Accessed February 18, 2017. 
24. Solo K, Mehra M, Dhawan R, Valant J, Scher HI. Prevalence of prostate cancer (PC) clinical states (CS) in the United States: Estimates using a dynamic progression model. J Clin Oncol. 2011;29(Suppl):Abstract 4637. Available at: http://media.hypersites.com/clients/1562/filemanager/docs/ Final\%20ASCO\%20Poster.June3.pdf. Accessed February 18, 2017.

25. XTANDI (enzalutamide) capsules for oral use. Prescribing information. Astellas Pharma U.S. Revised October 2016. Available at: http://www.astellas.us/docs/us/12A005-ENZ-WPI.pdf?v=1. Accessed February 18, 2017.

26. XOFIGO (radium-223 dichloride) injection. Prescribing information. Bayer. Revised May 2013. Available at: http://www.accessdata.fda.gov/drugsatfda_docs/label/2013/203971lbl.pdf. Accessed February 18, 2017.

27. ZYTIGA (abiraterone acetate) tablets for oral administration. Prescribing information. Janssen Biotech. Revised May 2016. Available at: https://www. zytigahcp.com/shared/product/zytiga/zytiga-prescribing-information.pdf. Accessed January, 2016.

28. Stevenson M, Jones ML, Kearns B, Littlewood C, Wong R. Cabazitaxel for the second-line treatment of hormone refractory, metastatic prostate cancer: a single technology appraisal. ScHARR, The University of Sheffield. 2011. Available at: https://www.nice.org.uk/guidance/ta255/documents/ prostate-cancer-cabazitaxel-evidence-review-group-report3. Accessed February 18, 2017

29. Academy of Managed Care Pharmacy. AMCP guide to pharmaceutical payment methods, 2013 update (version 3.0). Available at: http://www.amcp. org/pharmaceutical-payment-guide/. Accessed February 18, 2017.

30. Sorensen S, Ellis L, Wu Y, Hutchins V, Linnehan JE, Senbetta M. Budgetary impact on a U.S. health plan adopting abiraterone acetate plus prednisone for the treatment of patients with metastatic castration-resistant prostate cancer. J Manag Care Pharm. 2013;19(9):799-808. Available at: http://www.jmcp.org/doi/abs/10.18553/jmcp.2013.19.9.799.
31. MicroMedex Solutions. RED BOOK Online. 2015. Available at: http:// www.micromedexsolutions.com/home/dispatch. Accessed February 18, 2017.

32. Centers for Medicare \& Medicaid Services. July 2015 ASP drug pricing files. September 1, 2015. Available at: http://www.cms.gov/Medicare/ Medicare-Fee-for-Service-Part-B-Drugs/McrPartBDrugAvgSalesPrice/2015AS PFiles.html. Accessed February 18, 2017.

33. Centers for Medicare \& Medicaid Services. Medicare 2015 costs at a glance. Available at: http://www.themedicarechannel.com/docs/medicareataglance.pdf. Accessed February 18, 2017.

34. Centers for Medicare \& Medicaid Services. How to compare Medigap policies. Available at: http://www.medicare.gov/supplement-other-insurance/ compare-medigap/compare-medigap.html. Accessed February 18, 2017.

35. Medicare Payment Advisory Commission. Data book. Health care spending and the Medicare program. June 2014. Available at: http://67.59.137.244/ documents/Jun14DataBookEntireReport.pdf. Accessed February 18, 2017.

36. Kaiser Family Foundation. The Medicare Part D prescription drug benefit fact sheet. 2016. Available at: http://kff.org/medicare/fact-sheet/the-medicare-prescription-drug-benefit-fact-sheet/. Accessed February 18, 2017.

37. Q1Group. 2015 Medicare Part D - out-of-pocket cost calculator. 2015 Available at: http://www.qlmedicare.com/PartD-2015PartDCalculatorMedPartDXphp.php. Accessed February 18, 2017.

38. U.S. Bureau of Labor Statistics. CPI detailed report: data for April 2015. Table 25. 2015. Available at: http://www.bls.gov/cpi/\#data. Accessed February 18, 2017.

39. Optum360. National fee analyzer 2014.

40. XOFIGO (radium-223 dichloride). Storage and handling guide. Bayer. 2013. Available at: http://www.xofigo.com/hcp/assets/Xofigo_Storage_and_ Handling.pdf. Accessed February 18, 2017. 


\section{APPENDIX A Model Assumptions}

\begin{tabular}{|c|c|}
\hline Factor & Assumption \\
\hline Patient population & $\begin{array}{l}\text { When modeling patient out-of-pocket costs, assume all patients receiving treatment for } \\
\text { mCRPC follow a medical and prescription benefit that structures its copayments/coinsurance } \\
\text { in accordance with Medicare Part B, Part D, and Medigap. } \\
\text { Prevalence of prostate cancer within a managed care organization is similar to SEER program } \\
\text { prostate cancer prevalence data. } \\
1.2 \% \text { of mCRPC patients will receive second-line therapy following docetaxel. }\end{array}$ \\
\hline Treatment duration & $\begin{array}{l}\text { Assume median treatment durations as reported in clinical studies and that all treatment } \\
\text { cycles occur within } 1 \text { year. }\end{array}$ \\
\hline Medication adherence & Full adherence was assumed for all medications. \\
\hline Drug costs & $\begin{array}{l}\text { For cabazitaxel, treatment cost is modeled as average sales price plus } 6 \% \text {; for abiraterone and } \\
\text { enzalutamide, cost is modeled as average wholesale price minus } 16 \% \text {; and for radium-223, cost } \\
\text { is modeled as wholesale acquisition cost. } \\
\text { All patients in the model will exceed the Medicare catastrophic coverage limit in total annual } \\
\text { treatment costs. }\end{array}$ \\
\hline BSA or average weight for dosing & Base-case $\mathrm{BSA}=2.01 \mathrm{~m}^{2}$, average weight $=75 \mathrm{~kg}$ \\
\hline $\mathrm{AE}$ rates & $\begin{array}{l}\text { Assume that rates reported in clinical studies reflect the patient population and time horizon } \\
\text { (12 months). }\end{array}$ \\
\hline Current utilization rates as of January 2015 & Abiraterone 34\%, cabazitaxel 24\%, enzalutamide 26\%, radium-223 16\%. \\
\hline Estimated utilization rates in the theoretical future scenario & Abiraterone $30 \%$, cabazitaxel 33\%, enzalutamide $22 \%$, radium-223 15\%. \\
\hline Use of docetaxel & Assume that all patients have received docetaxel before model year. \\
\hline Treatment comparison & $\begin{array}{l}\text { The } 4 \text { model treatments have not been studied in a prospective, head-to-head trial in the } \\
\text { second-line setting. Comparative safety and efficacy are extrapolated from placebo-controlled } \\
\text { trials. }\end{array}$ \\
\hline Concomitant therapies & $\begin{array}{l}\text { Primary prophylactic use of granulocyte-colony stimulating for neutropenia among patients } \\
\text { receiving cabazitaxel was not permitted in the TROPIC trial and thus is not considered in the } \\
\text { model. } \\
\text { Concomitant corticosteroids constitute a negligible proportion of total medication costs } \\
(<0.02 \%) \text { and thus are not included in the model. }\end{array}$ \\
\hline
\end{tabular}


APPENDIX B One-Way Sensitivity Analyses for Difference in Average Annual Patient OOP Costs Versus Cabazitaxel ${ }^{a}$

\begin{tabular}{|c|c|c|c|}
\hline & Abiraterone, U.S. \$ & Enzalutamide, U.S. \$ & Radium-223, U.S. \$ \\
\hline Base case & $+4,313$ & $+4,797$ & +263 \\
\hline Average $\mathrm{BSA}=3.0 \mathrm{~m}^{2}$ & $+3,194$ & $+3,678$ & -856 \\
\hline Average BSA $=1.5 \mathrm{~m}^{2}$ & $+4,313$ & $+4,797$ & +263 \\
\hline Average body weight $=100 \mathrm{~kg}$ & $+4,313$ & $+4,797$ & +723 \\
\hline Average body weight $=50 \mathrm{~kg}$ & $+4,313$ & $+4,797$ & -197 \\
\hline Proportion of Medicare patients with supplementary insurance $=95 \%$ & $+4,878$ & $+5,361$ & +131 \\
\hline Proportion of Medicare patients with supplementary insurance $=55 \%$ & +363 & +847 & $+1,183$ \\
\hline
\end{tabular}
Proportion of Medicare patients with supplementary insurance $=55 \%$

${ }^{a} O O P$ costs for each agent minus OOP costs for cabazitaxel; a positive number indicates cost savings with cabazitaxel.

$B S A=$ body surface area; $m C R P C=$ metastatic castration-resistant prostate cancer; $O O P=$ out of pocket. 